\title{
A Review of Old Age Transitions and Social Protection in Sub Saharan Africa: Psycho-Social Dimensions of Growing Old in Western and African Contexts
}

\author{
Tani Emmanuel Lukong, Ph.D. \\ Educational psychologist at University of Buea, Fomic Polytechnic University and Founder, \\ "Foundation of Scientific Research, Community Based Rehabilitation and Advocacy on Inclusive \\ Education" (FORCAIE-Buea, Cameroon) \\ lukongemms_20@yahoo.com
}

\begin{abstract}
The striking improvement in medical facilities and living conditions, has led to many people being able to reach old age. This has called for more research within this developmental age. Psychologically, old age can either be viewed from a chronological age perspective, that is, the ages beginning from 60 or 65 and above or viewed from functional perspective, that is, performance in relation to age related physical, cognitive, social and emotional tasks. Whether chronological or functional, effective transition into old age is related to the social protection that is given to persons at the threshold of this developmental age. Due to physical, cognitive, social and emotional weaknesses experienced at this age, there need for public action to be sensitive to the needs of persons at old age.
\end{abstract}

Keywords: Old age Transition (psychological and social dimensions); social protection, cultural variations.

\section{INTRODUCTION}

This article examines the conceptual, theoretical and methodological issues that are related to old age and social protection. The paper focuses on Sub Saharan Africa (precisely Cameroon) as the bases of understanding the dichotomies between the psychological differences of the aging population in western and non-western countries. The chapter examines old age transitions and social protection as a psychological cohort, embracing issues related to physical, cognitive, social and emotional development and how society grapples with the problem of protection of old people. More specifically, this study addressed how people socially represent their aging transitions in Western and non-Western countries and how these countries differently protect aged people by public and private services. The non-Western countries taken into account were Sub-Saharan countries, with a particular attention to Cameroon elderly population. Finally, the study addressed psychological and social differences related to aging processes within different cultural contexts. Moreover, in order to better understand current conditions of global aging, this section takes into account international studies on both Western and African older populations, reporting data on resource and issues about economy, health and society. Finally, family characteristics, values, roles and issues will be addressed.

\section{BACKGROUND AND PROBLEM STATEMENT}

The number of people aged 65 or older is projected to grow until nearly 1.5 billion in 2050 (16\% of the world's population), with most of the increase in developing countries (WHO, 2011). This is generally due to a shift in the leading causes of disease and death, which depends on major changes in lifestyle and diet. While international studies allow us to consider the broad changes that occur in demographic data, global aging requires us to consider local and cultural implications of aging, too. Gergen (1999) explains that culture does not exist before people, but it is actively constructed by people and their mutual relationships: therefore, it is transitional and influenced by relational, social and historical variables. Moreover, the ways people co-construct reality through relationships influence their psychological functioning (Gergen, 1985). Considered this multifaceted idea of culture and relationships, it seems interesting to improve our understanding of aging processes by studying how people actively construct them among different countries. 
Considered that the way people actively construct their relational and cultural contexts by relating with other people influence their idea of self and their psychological state (Gergen, 1985; 1999), it is interesting to consider how psychological and sociological theories have addressed the issues related to aging. Aging processes, indeed, can be considered from different points of view. This section will give a general idea of the wide range of theories which can be taken into account when studying old age transitions, underlying how the major part of them lacks in considering the social construction of aging processes.

In order to engage in a solid discussion on old age transition and social protection in Sub-Saharan Africa and in order to understand the social and psychological differences of growing old in western and non-western countries, it is crucial for us to consider the contextual background of how old age has been perceived and the various social protection strategies that are used from a cross-cultural perspective. This contextual background provides an underpinning for possible conceptualization, theorization and empirical considerations.

In western societies, in contrast, the emphasis was youth-oriented and thus more negative views were held about the old. Despite the fact that the old were respected in Ancient Greece and Rome for their wisdom, there was a decline in this respect around the $5^{\text {th }}$ century BC (Hooyman \& Kiyak, 2011). Despite efforts made by Puritans thought to improve on the perception of old age as a gift from God, a shift from agricultural to industrialized economy especially in the US, gave powers to the young people who could work and make more money for the industrialized world. Old people were seen as less useful. The age of information technology that started in the 1980s have aggravated this negativity as the active population are the young adults not the old (Cowgill, 1986; Albert and Cattel, 1994). This negative perception of old age in Western society has left social protection of the old solely in the hands of the government. Old people are primarily catered for in institutionalized homes and they can receive sporadic visits from family members. This phenomenon is yet to find its place in Africa in general and Cameroon in particular.

In recent years there has been an increase in the number of people who reach old age. The psychological and social transitions that people at old experience is therefore a subject that requires much attention. Furthermore, there are cross-cultural differences and changing patterns within culture on the way old age is perceived which intend influences the social protection mechanisms that are put in place to cater for the needs of old people. In Africa, modernization has greatly changed the family structures from extended to more nuclear tendencies. This has grave consequences for people at old age, whose primary source of social protection in the past has been the family in its extended form. To add, the massive exodus of young people from villages to towns and abroad to search for white collar jobs have rendered old people more isolated and at the mercy government and public social protection (pension), which itself is plagued by multiple problems. Hence a need to investigate on the psychological and social transition to old age and how the changing cultural values have affected the perception old age and social protection for the old.

\section{Conceptual Reviews}

\subsection{Old Age Transition}

Old age transition constitutes the psychological and social changes that persons at the age of approximately $60-65$ begin to experience. These involve physical, cognitive, emotional and social changes that come as a result to aging. Let us examine the above aspects in greater detail.

\subsection{Physical Changes}

Before we engage into any discussion on changes in physical functionality at old age, it is important to note that physical decline is a general phenomenon at old age yet there are variations and individuals may experience this at various levels of intensity. Smith and Gove (2005) helps us to understand that the physical decline is a result of multiple factors such as sensory changes (hearing, vision, taste, smell and touch), changes in bones and muscles, digestion, blood circulation and sexuality. Statistics have shown that "about $30 \%$ of people over 60 have a hearing impairment, but about $33 \%$ of those 75 to $84, \ldots$ and about half of those over 85 , have a hearing loss ... furthermore, vision impairments such as cataracts, glaucoma, and blindness affect between $7 \%$ and $15 \%$ of older adults ... In addition, joints of older adults stiffen and connecting ligaments between bones lose their elasticity ... The older heart slows down and is less able to pump blood through the body than the younger heart" Smith and Gove 2005). 


\subsection{Cognitive Changes}

Unlike physical aspects where most organs can be affected by aging, cognitive decline is not experienced by the old in all domains. Cognitive decline is experienced specifically memory recall and speed of information processing. According to Kesinger (2005) older adults remain quite good with memory issues relating to familiarity and recognition but face problems with memory recall in relation to contextual details of an event. Furthermore, there is decline in the speed of information processing which underlie cognitive function. At old age, the mental operations become slow which makes it more difficult to encode and access previously processed information. Hence processing speed is regarded as the major deficit of aging (Kesinger, 2005).

\subsection{Social and Emotional Changes}

There is a close relationship between social and emotional wellbeing. The positive or negative manifestation of emotions largely depends on the social interactions we experience in our daily lives. Unlike the physical and cognitive declines that are experienced at old age, literature lean more on the fact that older adults are socially satisfied and emotional stable than younger adults (Carstensen, 1992).

Older adults tend to reduce the number of people they interact with. They prefer to narrow down their relationships to important peoples in their life and those that they have a strong emotional bond with. Hence, older adults report less emotional stressors than younger adults (Charles \& Piazza, 2007). Hence, despite the fact that reduction in size of social interactions with people can lead to isolation, intimacy in relations is more crucial in old age than the size of social interactions. Furthermore, old persons who are self-actualized tend to be more comfortable with the lives and are emotionally stable.

Hence, the fear of isolation, financial status, regrets of the past and the inevitability of death can be seen as important social and emotional issues that affect people at old age. The physical, cognitive, social and emotional changes that come with aging necessitate social policies to cater for the wellbeing of older adults. Their natural physical and cognitive losses that aggravate health and mental illnesses demand for compensatory strategies to help enhance their emotional and social capabilities. It is to this social protection mechanism for the old, that we now turn our attention.

\subsection{Social Protection}

According to the International Labor Organization (ILO, 2014)"social protection plays a particularly important role in realizing the human right to social security for older persons, in ensuring income security and access to essential services including health and care services in a way that promotes their rights and dignity" pp 1. Our review of social protection is centerd on two important issues. 1) Components of social protection for old persons and 2) sources of social protection.

\section{EMPIRICAL REVIEW}

\subsection{Components of Social Protection}

Basically, ILO (2012) outlines two important aspects of social protection for the old. First access to essential health care and secondly, income security.

\subsubsection{Income Security}

Public pension systems, in most countries are the foundation on which income security for the old is built. The importance of income security for the old is recognized by the 185 member states of ILO and endorsed by the G20. According to the recommendations, all countries must set social protection strategies that guarantee social security of all (ILO, 2012). Statistics show that on a global scale, only slightly more than half of older persons above statutory pensionable age (51.5 per cent) receive an old-age pension (i.e. periodic cash benefits) 1 , and if China is excluded the proportion falls to 45.6 per cent (ILO 2014). In sub-Saharan Africa, less than one in five older persons (16.9 per cent) receives an old-age pension which would provide him or her with a certain level of income security during old age. In the Middle East, 29.5 per cent of older persons receive a pension; the figure is 36.7 per cent in North Africa, 47.0 per cent in Asia and the Pacific (32.4 per cent excluding China), and 56.1 per cent in Latin America and the Caribbean (ILO 2014) 


\subsubsection{Health Care}

The medical care needs of older adults are often considerable. According to Bates et al (1995) approximately $80 \%$ of older adults require ongoing care for at least one chronic condition, $50 \%$ have multiple chronic conditions, and $60 \%$ are managing three or more prescription medications. Health care is therefore very important for old people. Accordingly, access to health care, discrimination, availability of doctors and acceptability stand our as major barriers to health care for old people. range of health services, therefore, is critically important for preventing new illnesses, adapting therapies to changing needs, potentially reducing acute care costs, and ultimately for maintaining the health and well-being of our aging population. This is supported by evidence to show that across 32 countries, 63 per cent of older people said they found it difficult to access healthcare when they needed it (Bates et al, 1995).

\section{Cross-Cultural Variations on Old Age Transition and Social Protection}

This section examines the differences that exist between Africa, Europe and the USA on some issues relating to old age transition and social protection. Our discussions shall highlight four important issues, namely, 1) the perception of old age, 2) healthcare and demographic conditions, 3) welfare policies, 4) family solidarity.

\subsection{African and Western Perception of Old Age}

The perception of old age within a particular culture largely depends on socialization values that are upheld in that particular cultural set up. In Africa, and particularly in Cameroon, emphasis is laid on communalism. Living together, working together, collective judgment and the absence of individuated things are major components of primitive African traditional values. Respect for hierarchy takes a pride of place within the African community. Hence the old are highly respected as men and women of wisdom. The young must listen to them.

The collective nature of the society, coupled with the idea of extended family, permits social protection for the old to be a communal affair (Zimmer and Dayton, 2003). Nevertheless in the past decades young people now migrate to towns in search for jobs, coupled with tendencies towards traveling abroad. Because of this phenomenon, social protection for old people who are now isolated in villages has become a matter of great concern for most African countries and Cameroon in particular. While the old are still highly respected, they face three major problems: 1) lack of proper family care due to the absence of young adults, 2) poor public pension and health care services, 3) the debate on the possible institutionalization of old people's homes (Nkwawir, 2010 ).

The Western society rather focuses more on individualistic tendencies, governed by high regard for economic values. With rapid growth in industrialization and information technology, the old are perceived as economically unproductive (Cowgill, 1986; Albert and Cattel, 1994). Institutions are therefore created to cater for the needs of old people insofar as they serve as avenues for more employment of the young. In western countries, old people are primarily catered for in institutionalized homes and they can receive sporadic visits from family members. This phenomenon is yet to find its place in Africa in general and Cameroon in particular.

\subsection{Healthcare and Demographic Conditions within USA, Europe and Africa}

Global aging is occurring in the context of the flow of human and economic capital, increasing across national boundaries, due to globalization (Harper, 2006). Therefore, aging processes interests both developed and developing countries, with meaningful changes across families, communities and policies.

Population aging influences economic markets, both at macro and micro levels. With regard to macro levels, it interacts with the value of labor, and with the increase of international flows of labor, capital and goods. With regard to micro levels, it influences labor productivity, consumption patterns and savings patterns: as young people who work and consume become less and less, economic growth gets slower. Moreover, there will be increased spending pensions. These conditions and concerns have different features and consequences depending on which country they occur in (Borsch-Supan, 2006). Moreover, global aging influences healthcare provision systems (Palmore et al., 2009).

With regard to developed countries, such as European countries and USA, major concerns are related to changes in product demand, as people in their 60 s will be still working and active, and this means 
they won't buy leisure and recreation goods, but household consumable goods and travel-related goods, as their younger coworkers (Harper, 2006b). For example, with reference to United States, Palmore (2009) reported that, despite US is one of the more active countries in the world for gerentological research and technologies, it still has some problems regarding social integration, health and economic status. As reported by Butler (2008) American elders have 16 years' life expectancy at age 65: this is less than that of 11 other industrialized countries. In Europe, the UK Office of National Statistics (2006) reported that the $21 \%$ of UK population is over the age 60 and Davidson (2009) stated that the percentage of people over 85 will increase from 1,9\% (1.1 million people) in 2001 to 3,5\% (2.2 million people) in 2021. The increasing percentage of over 80 people it is common across European countries: in Sweden and in Italy, which are the European countries with the higher rate of older population, life expectancy is over 80 years and is continuously increasing (Svensson et al., 2009; Cherubini et al., 2009).

The growth of old and oldest-old groups has a big influence on healthcare services provision: both in Usa and in Europe, formal care services are provided by governments, which are concerned about the cost of public health care (Martin, 2003). The costs are not related to population growth itself, but to the age structure, the lifestyles, the technologies and the environmental factors of each nation (Leeson, 2004). For example, Swedish services have different housing and healthcare services for younger-old and oldest old, which requires the efforts of three authorities: the social insurance office, the municipalities and the country council (Svensson et al., 2009); in Italy the healthcare is divided between the public long-term care system, nursing homes and informal family care, which is frequently supported by integrated health care services (physiotherapists, nurses, physician, psychologists and social workers who help families to take care of their oldest old; Cherubini et al., 2009).

With regard to developing countries, such as Sub-Saharan Africa (SSA), the old population is not as big as in developed countries: Aboderin et al. (2009) reported that only 4,8\% of the population is aged over 60. Despite this, SSA countries' populations are expected to increase in the next 30 years and, consequently, aged populations are expected to grow: for example, Mwangi (2009) stated that Kenyan elders population, which represents the $4 \%$ of general population, will increase over fivefold until 2050; Kakooza (2009) reported that Ugandan elders will increase from 1.7 million to 6 million by 2050; Kimuna reported that Zimbabwe's population aged over 60 will increase from 800,000 people to 1.5 million (9\% of the general population) by 2050; Fonchingong (2013) reported that in 2007 Cameroon's elder population constituted the $4 \%$ of the general population, but, as the $54 \%$ of the population is in the 15-64 age years range, this percentage is expected to increase in the next 30 years.

Within SSA countries, one of the major economic concerns is material security: the major part of older population hasn't a secure income. While $84 \%$ of older people in Europe and USA receive a pension, 5\%-20\% of older people receive it in developing countries (Harper, 2006a). Even in developed countries, were pension system gives older people some economic stability, the system seems to have been too generous and it risks to be no more affordable in the future. Within developing countries, economic poverty frequently matches with healthcare scarcity (Harper, 2006b). The major part of the population recourse to traditional healers, because healthcare resources (often provided by welfare state) are not enough. Population growth increases the rates of cardiovascular diseases and cancer, and governments are not able to face these public health issues, because they're seen as longterm diseases, when compared to AIDS and tropical diseases. At the moment, all the resources of developing governments address acute illnesses: for example, Kenyan government set up a fund to support elderly people who provide care to HIV/AIDS orphans (Mwangi, 2009).

\subsection{Welfare Policies in USA, Europe and Africa}

The ILO resolutions are mandatory to all member states to cater for the needs of the old. A survey carried out by ILO in 2011, 2012, 1013, and 2014 revealed that Statistically on a global scale, only slightly more than half of older persons above statutory pensionable age (51.5 per cent) receive an old-age pension. Nevertheless, these statistics show significant variations when broken down into regions. "In sub-Saharan Africa, less than one in five older persons (16.9 per cent) receives an old-age pension which would provide him or her with a certain level of income security during old age. In the Middle East, 29.5 per cent of older persons receive a pension; the figure is 36.7 per cent in North Africa, 47.0 per cent in Asia and the Pacific (32.4 per cent excluding China), and 56.1 per cent in 
Latin America and the Caribbean. Regional coverage ratios of more than 90 per cent of older persons are achieved only in North America and Europe" (ILO, 2014) pp 13 - 14. There is therefore need to cover the gap that exist between the western and African countries.

One of the first considerations made in order to compensate for global ageing within developing countries is using wisely the flow of people and capital: Howse (2006) suggested that two movements should be done - a capital movement from older regions (developed countries, like EU) to younger, in order to aid economic growth of developing countries, and a young people movement to older regions, in order to increase EU fertility rates. This would fix the actual gap between developed and developing countries, from an economic point of view. As different authors affirmed (Blake et al., 2004; Feld, 2005; Nyce et al., 2005), even from an economic perspective, this would be quite a lavish strategy, as it should rely on continuous flows. In addition, this wouldn't necessarily take into account social and health needs.

In order to further understand how developed and developing countries address elders' needs, we will consider the state of the art of public policies in USA, Europe and Africa.

With regard to USA, the state of aged people in the United States is not clear. While Schulz et al. (2006) reported that the vast majority of American elders live independently, in good health and economic conditions and can access to a wide range of facilities, Cook et al., (2012) underlined that in US there are many minorities, which vary considerably by income, ethnicity, location and life experiences. Therefore, economic support is not always provided by the State (who provide income to $20 \%$ of aged people), but it is more likely to be provided by Social Security programs or private sector plans (Cook et al., 2012). This is a big issue, considered that $10 \%$ of elders have incomes below the poverty threshold (Butler, 2008) and millions would like to find a job but are discriminated because of their age (Palmore et al., 2005). Moreover, Palmore (2009) underlined that a big discrepancy exists between resources available to elders' support programs and the realized programs. The great presence of minorities could be a reason for this: is not easy to properly support the needs of such an heterogeneous elders' populations (Palmore, 2009).

With regard to Europe, policy programs differ greatly from country to country. With reference to the UK, Taylor and Field (2007) stated that population aging can be summed up in four parts: increased survival of sick people, control of chronic disease progression (therefore increased years of life), improved health behavior and health status, emergency of very old and frail cohorts. A possible resolution could be the "Big Society" hypothesis, which combines the efforts of both political parties and general population in order to make social policies (Taylor et al., 2011). Moreover, informal support systems are common resources for the elders of European countries, such as Czech Republic (Topinkovà et al., 2009) where a National Program aims to support informal caregivers; in Italy (Cherubini et al., 2009), where families are already supported by an integrated healthcare system; in Denmark, the family support is increasingly rapidly (Munk, 2009).

With regard to Africa, Kpessa and Béland (2013), analyzed different policy models currently applied to sub-Saharan Africa needs and reactions to policy programs:

a) Industrialism describes social programs as derived by the economic and urbanization processes this is not true for African governments, which provide advanced social, educational and healthcare programs, despite their urbanization or economic levels (Adjibolosoo, 2007; Kpessa et al., 2013);

b) Power resource approach focuses on the role of political forces in implementing policies (Korpi, 1983) this theory could explain why the most part of African social programs are strictly related to the needs of the urban working class;

c) Historical Institutionalism takes into consideration the role political institutions have in creating boundaries and opportunities to policy makers and community movements (Skocpol, 1992; Amenta, 1998) this is one of the least fightable approaches to African community, as social programs in Africa are created within informal contexts, and are not always formally politicized;

d) Cultural and Ideational Perspective approach focuses the impact of shared values and world views on policies programs (Campbell, 2002) this model could be useful, because taking into account the impact of cultural values on the implementation and expansion of policy programs could explain why, within some rural contexts, the advancement in social programs is not supported (a possible explanation is that traditional family is viewed as the main provider of social assistance, within 
rural regions; Apt, 2002; Kraus, 2007). Moreover, a more culture-focused approach could effectively take into account gender and ethnic issues, such as the exclusion of women from the policy making processes, or discrimination against specific ethnic groups in the provision of social services (Fanon, 2004).

On a continental basis, the African Union created in 2002 the African Union Policy Framework and Plan of Action on Ageing (PFPA). The plan is a sort of guide for member States to maximize their ability to design, implement and evaluate national policies within 4 areas: rights; poverty and income security; health, social welfare and role of the family; information and coordination of policy development. In 2005 this initiative was reinforced by the creation of the Economic Social and Cultural Council, which wants to increase communication and partnership between governments and civil society stakeholders.

On a national basis, each nation has adapted his plans according to the guidelines, taking into account political parties, priorities, specific conditions of elder population, and capacity of government and community to engage. Obviously, some countries show more progress than others. Zimbabwe, for example, shows a big discrepancy between urban and rural welfare assistance: people in rural areas have no access to assistance services, mostly because rural elders don't know about social security pension schemes or experience difficulties to get to nearest office (Kimuna, 2009). South Africa, instead, is one of the middle income countries which have the highest rate of growth for social protection policies. Social protection policies include contributory social insurance schemes (life curse and employment risks), non-contributory social assistance programs (poverty and vulnerability) and labor market and employment policies (Barrientos et al., 2013).

Generally speaking, African countries can turn to both formal and informal social protection systems. Formal systems are made of: 1) social insurance plans, which ensure people who paid contributions to receive financial support if they suffer from a shock or a permanent change in their circumstances; 2) social assistance plans, which are related to non-contributory transfers, to people in conditions of vulnerability or poverty; 3 ) standards plans, which aim to set and increase minimum standards to protect working citizens. Informal systems are the most common systems used in Africa: social protection is usually provided by extended family, traditional solidarity networks, co-operative and social associations, self-help groups and credit clubs (Olivier et al., 2004). Apart from family, one of the most important providers of social support for older people is civil society.

Civil society organizations are in partnership with public and private sectors, in order to advocate aging issues, above all in urban areas. For example, in some parts of Zimbabwe the concept of ZunderaMambo (literally "the Chief's Granary") has been introduced: it refers to the harvest of a common field stored in a common granary and used at discretion of the chief, with the aim to ensure the community sufficient food (Dhemba et al., 2002; Kimuna, 2009).

In sum, despite the activities of governments, organizations and associations, families still have a main role in social support programs, cultural contexts and policy making processes, both developed and developing countries. For these reasons, we are going to consider how family solidarity affects older people conditions in African countries, which roles family covers within developed countries and how family contributes to the social construction of old age within African regions.

\subsection{Family Solidarity within Europe, USA and Africa}

Recent demographic studies on European and US families (Bengston, 2001; Harper, 2004) have shown that families are becoming more multigenerational with a reduction of horizontal members (siblings, cousins, uncles, aunts) and increase of vertical members (grandparents and grandchildren, great-grandparents and great-grandchildren). The actual concern is that emotional stress will get higher as the number of old people increase. Moreover, old people will rely on younger members to receive support, even if, at the same time, fertility rates are exponentially decreasing.

In addition, the configurations of families and households are changing and fragmenting. Even within nuclear families, there are many family-household combinations. Despite this, studies show that people consider family as a main actor in socialization processes (Hughes et al., 2004) and as source of support for both children and elders (Logan et al., 1996; Bengston, 2001; Leeson, 2004). US and Europe data report that values related to intergenerational support are still strong and sound (Philp, 2001). This demonstrates that, despite new living arrangements and needs, family still play an important role in later life. 
In order to understand what the perception of family support is in developed countries, many scholars studied intergenerational family solidarity and family conflict. In the last 30 years, three models of parent-child relations in adulthood were proposed: 1) Intergenerational solidarity in later life; 2) Intergeneration conflict in later life; 3) Intergenerational ambivalence in later life. The intergenerational solidarity model was first proposed in 1970s and it's a sort of classification of sentiments, behaviors and attitudes in family relationships (Roberts et al., 1990). Originally, six dimensions were considered as descriptive of family solidarity: association, affect, consensus, function, normative solidarity and family structure (Bengston et al., 1982).

Consequently, these dimensions were gathered into two factors: 1) structural-behavioral (association, function, structure) and 2) affective-cognitive (affect, consensus, normative solidarity). The models consider family cohesion as an important component of family relations, with main effects on elder's well-being (Silverstein et al., 1994) and longevity (Silverstein et al., 1991). Despite this, the model has two main limitations: it defines cohesion in terms of "solidarity", which implies consensus on giving support (Marshall et al., 1993); and it doesn't take into account conflict (Luescher et al., 1998). The second approach, the intergenerational conflict model (Bengston et al., 2001) take conflict into account, even considering the possible negative effects of a high spread of solidarity action within the family (Silverstein et al., 1996).

The main idea is that conflict is not a problem itself: it is a normal aspect of family relations, but, as it affects the way family members perceive one another, it has a main role in the willingness each member has to support others. Solidarity and conflict are not a continuum: family could show both high solidarity and high conflict, both low solidarity and low conflict, or different levels of each variable. Finally, the ambivalence approach (Luescher et al., 1998) focuses on contradictions and ambiguities in relationships. The main idea is that ambivalence is due to the connection among individual experiences, social relationships, institutions and societal change (Connidis et al., 2002).

In a study on 1200 family members from Norway, England, Spain, Germany and Israel, Lowenstein (2007) showed that the most part of respondents in all countries reported strong solidarity (in the affective and cognitive components), and negative intergenerational emotions (conflict and ambivalence). The research showed that in developed cross-cultural contexts extended families have still a strong intergenerational cohesion, even with ambivalent feelings and some conflict.

The traditional model of families within developing nations is fairly different than the traditional Western nuclear family. The African extended family often includes people from the actual family and other individuals which have no biological links, but are considered as family members anyway (Ross, 1996). Aged people often report to consider people they know and feel close to their family as their children and grandchildren: "He's got no parents, got nothing. Yes, I took him to come and stay with me, look after me. I'm looking after him. He's looking after me." (Aged woman, in Bohman et al., 2009, p.450).

Besides this traditional model, Schatz et al., (2015) report that East and South Africa have a long history of fragmented families, meaning that, because of the migration of intermediate generation adults from rural areas to cities, rural regions show higher rates of older people and children. Usually, as men are required to have a job, while women to look after children, the major part of the adults living in rural areas are women (Madhavan, 2004). With westernization, even young women start searching for job going to cities: this phenomenon gets the rates of middle-age adults in rural contexts lower and lower (Cross et al., 2006; Haour-Knipe, 2009). Extended-fragmented families often include children born outside of marriage, who usually rose by grandparents, as having children outside the marriage set off social mothering (Makoni, 2008; Harrison et al., 2013).

Through developing countries is raising the awareness that the traditional model of extended family can become vulnerable, because of the main changes of the last years. Despite this, Help Age International (2002) showed that elders members often are coresident with younger family members and, even in non-co-resident families, support to elders (by sharing money and goods) has a great importance. Moreover, some studies (e.g. Bohman et al., 2009) showed that, in most families, younger family members are economically and emotionally dependent from elders, and that old age people is highly involved in decision-making processes within the family.

At the best of our knowledge, psychosocial and anthropological studies about family solidarity within developing countries have emphasized the emergence of an intergenerational gap, recognized by both 
younger and older generations. As reported by Cattell (2008), Kenyan old people complain that "The young don't want to talk with us" or "Young people just want to speak English" (Cattell, 2008, p. 195). Aged people have been educated by their grandparents during their childhood, and try to do the same with their grandchildren. Somehow, they feel as a sort of a "stabilizing factor" (Bohman et al., 2009), and educate the younger members of their families through storytelling, which help them communicate traditional values.

Therefore, talk with elders and listen to them it's perceived by the elders as a way to show them respect. At the same time, younger members have a different idea of respect: "It is not a question of losing respect. We have to keep our norms and values. We are westernized; our customs are just for weddings and funerals" (Grandchild; Bohman et al., 2009). The feeling that traditional norms, values and customs are somehow poor related to contemporary times is common within African younger generations (Bohman et al., 2009).

Despite the gap, intergenerational support is still a main issue within African contexts. As widely reported, Africa is facing a care deficit, due to the poor coordination among states, families and private services (Zimmerman et al., 2006): formal care is poor in rural centers, or it is accessible to elites only (UN-FPA, 2002); paid services are often unaffordable to old people (Akintola, 2004; Heymann et al., 2009); and often states can't provide proper care services, even in urban areas (NinoZarazùa et al., 2012). Therefore, families are the best provider of informal care for children, sick and aged (Mathambo et al., 2009; Ritcher et al., 2009; Apt, 2012; Thrush et al., 2014). At the same time, family care giving is strictly related to family struggling to balance the needs of all family members. Both younger and older generations provide and receive care from others. As reported by Schatz et al. (2015), these conditions bring about three consequences:

1) Older people need care, but within some African regions middle-younger generations suffer from HIV and related illness: this often results in a lack of informal care systems;

2) For the same reason (HIV spreading within middle generations) the care older people provide is crucial to raise up grandchildren (Deininger et al., 2003; Kautz et al., 2010). Some studies reported that more that $60 \%$ of children orphans because of AIDS live with grandparents in Namibia, South Africa and Zimbabwe (Apt, 2012; Zimmer et al., 2005).

3) As they age, older people will need more and more support, as health problems are mainly shifting to non-communicable diseases.

Generally speaking, a broad range of studies show that elders provide economic and emotional support to younger generations. Bohman et al., (2007) showed that in South Africa elders are often the only family members who receive a regular income, usually from the pension system, and share it with other members of the extended family, or use it to provide healthcare to ill members. Moreover, as reported by the authors, caring is a sign of respect (Moeller et al., 2002), both for elders and younger members of the family, and culturally, elders who provide care for their grandchildren are actually emphasizing its value within the extended family, hoping that their care towards younger members will be reciprocated. Indeed, even if the traditional values require to look after old members when we they are in need, future care is not perceived as granted by the elders, who feel like some changes related to "westernization" (geographical separation, nuclear families) are a proof of lacking love and respect towards them (Bohman et al., 2009).

With reference to the HIV care giving issues, they are generally related to 1) young children, orphans or with sick parents; 2) sick adults and 3) older people whose caregivers died of HIV. More specifically, Knodel and colleagues individuated seven ways through which HIV could impact on older people: care giving, co-residence with an adult child suffering from AIDS, providing the adult child financial and material support during the illness, loss of the adult child, paying for the funeral of the deceased child, raising up grandchildren, negative community reactions.

Demographic studies show that living arrangements are often modified in order to allow elder people, their adult children and their grandchildren to live all together in the same household (Merli et al., 2006). As widely reported in the literature (Bicego et al., 2003; Bohman et al., 2007; Ssengonzi, 2009), older people are required to engage physically, financially and emotionally by caring for children and sick adults, and often without receiving help from other members of the middle generation (Hosegood et al., 2005; Seeley et al., 2009). Moreover, as reported by Kautz et al. (2010), 
elders who live in countries with high rates of HIV are more likely to live alone and without care, compared to peers in region with lower HIV rates.

Schatz et al., (2015) reviewed the benefits and disadvantages of care work in African contexts. Negative effects on older caregivers include both financial and emotional aspects. Elders frequently can't afford the expenses related to caregiving, reaching poverty (Lindsey et al., 2003), or can't engage in informal remunerative activities, like agriculture, because they need to spend their time looking after grandchildren or sick family members (Yajima et al., 2010). Moreover, being a caregiver influences health and well-being. Several studies report high levels of stress, depression and exhaustion (Akintola, 2004; Orner, 2006), often associated with physical fatigue and general poor physical health (e.g. Oburu et al., 2005). In addition, providing care to HIV ill people is often related to social isolation, stigma and discrimination (Howard et al., 2006; Ogunmefun et al., 2011).

At the same time, care giving may have some positive effects, too. Some common benefits are feeling satisfied from care work (Brown et al., 2014), feeling emotional and spiritual strength (Abel, 2000), receiving support when needed (Casale, 2011; Mugisha et al., 2013). The reciprocity issue is crucial: in most of the situations, elder people who provide emotional and financial care to grandchildren receive material support from them (e.g. collecting water or firewood; Evans, 2010; Abebe et al., 2010). In turn, reciprocity increase emotional well-being, as elders feel supported, have hope for the future (that someone will care for them; Schatz et al., 2007), experience joy from having a child in the family (Howard et al., 2006).

A main aspect of carework, both in developed and developing countries, is that providing care is a gendered work. As reported by Calasanti (2010), gender identity is shaped by local norms and values, and influences the way older people describe themselves and how they act within family and community (even carework). African cultural beliefs about features and roles of men and women require women to show "maternal instinct" and men to be "breadwinners" (Oppong, 2006): then, while women are expected to provide care to children and sick, men are expected to provide economic support (Cancian et al., 2000). Traditional values and roles have two consequences:

Women care work is often taken for granted, and women's issues and difficulties are not considered by family members and community in general. This leads to a condition that in Western countries is called "sandwiched generation", referring to middle-aged women caregivers who have to raise their own children and care for sick parents at the same time (Ingersoll-Dayton et al., 2001). Within African contexts, women are not "sandwiched" between generations, but are still contemporary caring for the next two generations beyond them;

As the need of care work gets higher and higher, men have the face the conflict between the cultural definition of masculinity (spend old age doing leisure activities; Whitehead, 2000; Munthree et al., 2010) and the actual needs of their families. For these reasons, they frequently have to engage in providing emotional and physical support to children and/or sick members of the family (Munthree et al., 2011). From a social and cultural point of view, as men's physical and emotional care work is not expected because of normative roles, it is more visible, too.

\section{Changing Pattern of Family and Social Protection for the Old in Africa: MODERNIZATION AND SOCIAL CONSTRAINT EXPLANATIONS}

Modernization theory is one of the best known (and mostly refused) theories on the evolution of family roles. The main idea of this approach is that, as the economy grows, the support and social status of elders decline (Burgess, 1960). Generally speaking, the modernization theory suggests that industrialization and urbanization processes, formal education and secularization brought some changes to familiar assets: family lose its importance as an economic unit, jobs of older people became obsolete, family member were geographically separated, younger generations became more educated than older ones, individualism increased. All these processes yielded to the loss of status and roles of older people, both in family and societies: they lose authority and, in turn, this weakened the norm of filial obligation towards parents/older member of families.

Moreover, younger generations "abandoned" origin and extended families, in order to give more attention to their nuclear families. Aboderin (2004) suggests that this approach was created within the context of Second World War in response to the lower status of old people and the increasing divorce rates in Western developed countries (Aboderin, 2004). During 1970s, Cowgill (1972; 1974) proposed a cross-cultural version of the approach, still considering the development from traditional to modern societies as a linear path. 
Despite these theoretical and contextual limitations, during 1970s and 1980s modernization and its impact on elders social status have been the most common approach to the aging process within developed countries, until a large body of research showed that the idea of an "abandoned" aged population didn't suit actual perceptions of families (Fennell et al., 1988; Glascock, 1990; O'Rand, 1990; Marshall et al., 1993). Moreover, modernization theory created a sort of "prediction" about the future of developing countries: the more they "modernize" the less respect and status the elders would have had. Starting from this point, developed countries started a long debate about the future role of aging people within developing countries (United Nations, 1982; Sen, 1994).

Even if the modernization approach has already been refused within developed countries, the major part of Western scholars applied it to developing nations, despite a wide range of studies demonstrates that, even if families are adapting to new cultural and social contexts, family values remain intact (Hashimoto, 1993). Aboderin (2004) suggests that in the West this theory allowed people to explain the 19th century decline in family financial support and was followed by the institution of state pension; in developing countries resulted as a good explanation to the increasing general poverty and the lower ability of families to support their elders.

Actually, it is possible that the declining of younger generations support for older people is not due to the loss of traditional values, or the unwillingness of the younger member of the families, but it could be owing to a growing incapacity to respond to older people needs. This hypothesis is referred as "material constraints" notion (De Lehr, 1992). The main idea of this approach is that economic changes (increasing costs of living and more spread poverty) can result in economic stagnation and this could lead to a lower family support, as younger generations give priority to nuclear families (Treas et al., 1986).

Both these theories have some important limitations in the explanation of family support to older people. First, each of them doesn't consider the focus of the other: modernization theory doesn't take into account economic constraints, while material constraints approach doesn't consider the implications of values and social norms. Moreover, both these theories describe this phenomenon from a macro-level of explanation. They don't take into account the intentions, the motives and purposes of individuals, neither how they situate in their contexts of living (Ryff, 1986; Strauss et al., 1990; Giddens, 1991). In order to overcome these limitations, Aboderin (2004) proposes to focus on three aspects: motives, explanations and interpretations of younger and older people before the reduction of support, motives, interpretations and explanations in the present moment, and the comparison between the two moments, in order to understand how changes have occurred in the opinion of both generations and which values, norms and contextual changes supported this modification.

\section{Theoretical Considerations}

This article articulates some theoretical perspectives that are relevant to old age transition and social protection.

\subsection{Gergen's Theory of Social Construction (1985)}

As briefly stated before, the theoretical framework of this study is Gergen's theory of Social Construction (Gergen, 1985). Gergen critiqued social sciences, arguing that social knowledge is not grounded in empirical facts, because there's no objective reality to verify: social behavior is always embedded to historical conditions, therefore its explanations are influenced by historical situations and values as well (Gergen et al., 1980). Gergen's response to these issues is social constructionism (Gergen, 1994; Gergen et al., 1997). Gergen's theories, indeed, takes into consideration cultural values and social processes. The main idea is that social processes in which people are involved help them construct their understanding of the world, through discourses and dialogues. Therefore, cultural values are fluctuating and transitional, related to human relationships than construct them. There aren't common, fixed values: people construct values around social phenomenon and, within each specific cultural context, actively create its own values. There's no one knowledge or truth to be discovered or known, neither rules or norms to be respected: as social life is continually changing, words, concepts and meanings do the same (Gergen, 1973). The main tool by which the construction is achieved is language, as by talking people stress and emphasize some aspects of reality, and ignore others (Gergen refers to this process as "binary distinction"; see Gergen, 1999, p.27). 
Gergen (1999) proposed five basic assumptions of social constructionism:

1) The way in which we understand the word is not required by "what there is". "We are not locked within any convention of understanding" (Gergen, 1999, p.6): it is not possible to consider a topic in terms of what that thing is, but it is possible to study how the people who experience that phenomenon contribute to construct and give meaning to it.

2) The ways in which we describe and explain the world are the outcomes of relationship. Each person knows the world through experience with others and, therefore, contributes to the construction of the world communicating with others within the relationships he/she takes part. Language is a picture: using it, we depict reality.

3) Constructions gain their significance from their social utility. As we relate one another, we develop some pattern of communication and coordination which are more or less acceptable, depending on conditions and situations in which they occur. At the same time, different people can construct differently the meaning of each situation and condition, so that "for any situation multiple constructions are possible" (Gegen, 1999, p. 10).

4) As we describe and explain, so do we fashion our future. The link between relationships and practice of language have some important influences: on one side, the meanings and words we use within social relationships influence the way we see and interpret the world, on the other, our relationships influence that world, changing its meaning. This process is resourceful and threatening at the same time: it depends on how we use words and meanings. Moreover, this process is meaningful and crucial within this era, in which change is constant and involves any area of individual and community lives.

5) Reflection on our taken-for-granted worlds is vital to our future well-being. Gergen (1999) proposed two challenges: one is related to maintaining traditions; the other is to create alternative futures. Given that there's no fixed "good values" or "good traditions", it's still true that tradition welcomes transitions and changes, only when they're profoundly related to them.

With reference to aging process, while from a scientific-biological point of view, aging process responds to common decline norms (e.g., Erikson, 1963), from a constructionist approach, "there's no process of aging in itself; the discourse of aging is born of relations within a given culture in a given time" (Hazan, 1994, in Gergen, 2000, p. 3). Hazan (1994) highlights how the common idea that aging constitutes an individual and social problem is due to the assumption that there's a deep gap between the aged and society. Do the aged perceive that gap? Do the societies they live in actually produce that gap? And these perceptions and constructions are the same within any country? Obviously not. That's why we'll consider the contents of other social-psychological theories of aging from a constructionist point of view, considering the disadvantages of these approaches.

The main issue of classical theories about old age is the strong relationship to demographic theories and studies. Demographic approaches aim to explain how rates of fertility and mortality change through time and countries, how illness and death are spread in most countries, and which are the causes of spreading (Feacham et al., 1992). A similar approach deals with "mortality transition", more than "old age transitions" (Kahn et al., 2006). For this reason some authors tried, even considering demographic variables, to take into account different aspects of aging. The theories emerged from this broader approach include the Theory of Epidemiological Transitions (Omran, 1971; Omran et al., 1982), the Theories of Social-Economic Classification and the Theory of Gerotranscendence (Tornstam, 2003).

\subsection{Omran'sTheory of Epidemiological Transitions (1971)}

Omran's model of epidemiological transitions considered how morbidity patterns interact with social and economic variables (Omran, 1971).The theory states that each society goes through three transitional stages: 1) Era of pestilence and famine, characterized by high mortality, high rates of infections and nutritional disorders - because of the common complications of pregnancy and childbirth, the life expectancy of men is higher than women's; 2) Era of receding pandemics, in which mortality rates reduce and population growth increases; 3) Era of degenerative and man-made diseases, in which mortality rates are overall low (with a peak at older ages), both for women and men. During 80's Omran and colleagues (1982) added a fourth stage, related to the reduction of degenerative disorders, which, in turn, are related to lower age-specific deaths. 
Moreover, Omran described three basic models of epidemiological transitions: 1) Classical (Western) model, in which, progressively, the higher the socioeconomic development, the higher fertility rates and the lower mortality rates are - this model is typical of most Western European societies, and is enhanced by advances in medical technology; 2) Accelerated model, in which fertility rates and socioeconomic development increase rapidly - this model describes Japan and Eastern European countries' transitions; 3) Contemporary or delayed model, typical of countries with ongoing transitions - within these populations, transitions are owing to the spread of public health interventions.

The model presents some main issues, related to the lack of consideration of medical and public health discoveries and interventions (Caldwell, 2001) and to the unrealistic idea that health and aging trends follow a regular pattern, apart from cultural, social and historical local variables (Gaylin et al., 1997). As stated by Gergen (2000), each person has an active role in modeling his aging process: even if historical events take place on a macro-level, the actual aging process depends on relational and cultural contexts constructed by each elder.

\subsection{Tornstam's Theory of Gerotranscendence (2003)}

The theory of gerotranscendence (Tornstam, 2003) takes the effort to consider both the older person and the dynamic ageing process. It involves three dimensions: 1) the cosmic dimension of transcendence, related to feeling as a part of the universe, having less fear of death, accept the mystery of life; 2) the dimension of self, related to a new ability to see one's own life and give it a new meaning, considering how episodes influenced oneself as a person; 3) the social and personal relationships, related to the need for solitude, the selective choice of activities and close relationships. Despite the fact that this theory has a more contextual approach to aging transitions, Tornstam describe an "ideal" aged person: s/he is wise, accepting, and thoughtful. The truth is that each individual ages within different social-cultural contexts and each person constructs his/her own aging process within his/her environment.

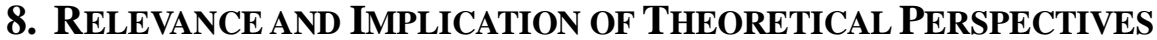

The social construction theory of aging assumes that the way aged people are treated by other and represent themselves depends on how they construct their social status with people they interact with: they can be more or less impaired, more or less retired, and more or less productive. Gergen \& Gergen (2006) individuated four main variables that influence the way elder people construct their own aging process and status: relational resources, physical well-being, positive mental states and engaging activities. Each variables has bidirectional links with others. Relations influence physical well-being (by encouraging elder in going on a diet, in exercising or in seeking professional advice) and elders who feel healthy are more likely to engage in relationships with others: widowed women who receive social support have a better health status (Stroebe and Stroebe, 1996) and recover more easily from injuries (Kempen et al., 2001); and elder people with strong relationships recover more easily from loss (Abbey et al., 1985). Relationships influence positive mental states, too, as they improve selfconfidence and the sense of self-worthiness; at the same time, positive mental states increase the likelihood and the intention to relate with others. Some studies (e.g. Pierce et al., 2000) showed that people high in social contact are more likely to feel supported and less likely to become depressed. Positive mental states influence engaging activities, as they provide a sense of purpose and optimism; at the same time, engaging activities improve the quantity and the quality of positive mental states (Prenda et al., 2001).

Moreover, positive mental states influence physical well-being, feeling good in mental states influence feeling good in physical states, for example influencing risk to develop diseases (Ostir et al., 2001), or increasing life expectation (Harker et al., 2001). Even physical well-being influence engaging activities, and vice versa, as engaging activities (both physical and social) improve physical health. Finally, relational resources influence engaging activities, as knowing lots of people is both a starting point to broaden one's own interests and a result of being engaged in a range of activities. It is important to consider that these relations are not described by the authors in terms of predictions: the main idea of positive aging is not to find universal truths about ageing, by stressing that each of the four variables described above are related each other and can help elders to actively construct positive aging processes (Gergen \& Gergen, 2002). 
As stated by Gergen \& Gergen (2006), in a social constructionist perspective all the influences are related to relational resources, as people interpret and represent their reality starting from the relationships they create. For example, if a community shares the idea that having a restricted movement is normal in certain conditions, then that feature is no longer "impairment". Finally, positive aging model can influence policy making, promoting programs that address all the four variables proposed. For example, it could be useful to stop considering menopause as a medical problem, by addressing the social, relational and psychological implication of this major change (Gergen \& Gergen, 2006).

In sum, the classical theories of aging don't take into account how aged people actively construct their health, social, psychological and economic conditions by interacting with others and engaging in their communities. Gergen's social constructionist theory can be a useful theoretical framework to get over a positivist-empiricist (Gergen, 1979) idea of aging processes and understand how elders construct meaning about aging in their specific communities.

Despite their limitations, all the theories considered above emphasize the importance of using knowledge in order to implement useful and effective public social and health programs, which actually respond to population needs. Moreover, social constructionist suggests taking into account how each specific population constructs its own values and practices, within its cultural and social context. As stated by Gergen \& Gergen(2000), the cultural values related to aging and that derived from aging are not fixed: they are subject to fluctuation and transformation created by the aging population itself. Moreover, values are generated from relationships: the more values are linked to relatedness, the more they are likely to prevail over exterior values (Gergen et al., 2000). With a profound knowledge of the conceptual and theoretical literature on old age transition and social protection, we now turn our attention to the methodological options that underpinned our empirical inference to achieve the objectives of the study.

\section{Conclusion}

Within African cultures, Eboiyeyi (2015) makes us to understand that the aged are construed as mediators between the present and the next worlds. As guardians of the tradition of the people, they are representatives of the ancestors. Those who live righteously are blessed by the ancestors to live till old age, which permits them to see their grandchildren. Though old are physically weak, they are endowed with wisdom. The young come around the old to gather this wisdom in order to prepare themselves for a journey which the old have already achieved. Consequently, social protection was imperative and culturally permissible. This social protection in the form of care for the old came primarily from the family (Zimmer and Dayton, 2003). Due to the concept of extended family, the old could expect care not only from the immediate family but from the society at large. Nonetheless, the contemporary experience reveal a cultural shift from collectivism to individualism, hence social protection may only come from the immediate family and government structures that are blessed with limitations. In the case of Cameroon, social protection comes through pension via the CNPS is plagued with problems ranging from delays in payments, sharp financial disparity between public and private workers, poor implementation of labor laws etc. (Nkwawir, 2010 ). These poor services leave social care for the old in the hands of immediate family members. The issue becomes more complex when we consider the massive numbers of youth that leave villages to search for greener pastures in towns, coupled with the zeal to travel abroad, hence the old are abandoned in the villages, with little or no care and protection. In conclusion, the psychological dimensions of old age transition and the components/sources of social protection are influenced by and vary from one culture to another. The cultural perception of persons at old age play a significant role in transition elements and social protection mechanisms that are put in place by each society to cater for the rights of old persons. We shall attempt a cross cultural survey of perceptions of old age and social protection.

\section{REFERENCES}

Abbey, A., \& Andrews, F. M. (1985). Modeling the psychological determinants of life quality. Social indictors research, 16(1), 1-34.Aged Among The Esan Of South-South Nigeria. The Journal of International Social Research. Vol 8. Pp 340 -356

Albert\& M.G. Cattell, (1994). Old age in global perspective. New York: G.K. Hall and Co. Bates DW, Cullen DJ, Laird N, Petersen LA, Small SD, Servi D, Laffel G, Sweitzer BJ, Shea BF, 
Butler, R. N., Miller, R. A., Perry, D., Carnes, B. A., Williams, T. F., Cassel, C.\&Olshansky, S. J. (2008). New model of health promotion and disease prevention for the 21st century. Bmj, 337.

Carstensen, L. L. (1992). Social and emotional patterns in adulthood: Support for socioemotional selectivity theory. Psychology and Aging. 7: pp 331-338.

Charles, S. T. \& Piazza, J. R. (2007). Memories of social interactions: Age differences in emotional intensity. Psychology and Aging.22: pp 300-309.

Cook, I. G., \& Halsall, J. (2011). Aging in comparative perspective: Processes and policies (Vol. 1). Springer Science \& Business Media.

Cowgill, D.O. (1986). Aging Around the World, Belmont, CA: Wadsworth Inc.

Eboiyehi F. A. (2015). Perception Of Old Age: Its Implications For Care And Support For The

Feldman, R. S. (2003). Development Across the Life Span. ( $3^{\text {rd }}$ ed) Upper Saddle River, New Jersey.

Gergen, M. M. and K. J. Gergen (2002). Positive ageing: New images for a new age. Ageing Inte national 27(1), 3-23.

Gergen, M., \&Gergen, K. (2006). Positive aging: Reconstructing the life course. Handbook of girls' and women's psychological health: Gender and well-being across the life span, 416-426.

Hallisey R, et al. (1995). Incidence of adverse drug events and potential adverse drug events. Implications for prevention. ADE Prevention Study Group. JAMA274: pp 29-34.

Harker, L., \&Keltner, D. (2001). Expressions of positive emotion in women's college yearbook pictures and their relationship to personality and life outcomes across adulthood. Journal of personality and social psychology,80(1), 112.

Hooyman, N. \&Kiyak H. A. (2011). Social Gerontology : A Multidisciplinary New Edition. Available online:http://www.mybookezzz.com/social-gerontology-9th-edition-by-hooyman/

ILO. (2011). Social security for social justice and a fair globalization: Recurrent discussion on social protection (social security) under the ILO Declaration on Social Justice for a Fair Globalization, 2011, Report VI, International Labour Conference, 100th Session, Geneva, 2011 (Geneva). Available at: http://ilo.org/ilc/ILCSessions/100thSession/on-the-agenda/socialprotection/lang--en/index.htm.

ILO. (2012). Social Security for All: Building social protection floors and comprehensive social security systems. The strategy of the International Labour Organization (Geneva: International Labour Office), Available at: http://www.socialsecurityextension.org/gimi/gess/RessFile Download.do?ressourceId=34188.

ILO. (2013). Global Wage Report 2012/13: Wages and equitable growth (Geneva). Available at: http://www.ilo.org/global/research/global-reports/global-wagereport/2012/WCMS_194843/lang--de/index.htm [16 Apr. 2014].

ILO.(2014). Social protection for older persons: Key policy trends and statistics. International Labour Office, Social Protection Department. - Geneva: ILO, 2014 (Social protection policy paper ; No. 11, ISSN: 1020-9581; 1020-959X (web pdf) ) ISBN: 9789221292012 ; 9789221292029 (web pdf)

Kempen, G. I., Scaf-Klomp, W., Ranchor, A. V., Sanderman, R., \&Ormel, J. (2001). Social Predictors of Recovery in Late Middle-Aged and Older Persons After Injury to the Extremities A Prospective Study. The Journals of Gerontology Series B: Psychological Sciences and Social Sciences, 56(4), S229-S236.

Kensinger, E. A. (2005). Cognition In Aging And Age-Related Disease.Boston College, McGuinn Hall

Mwangi, S. M. (2009). History Of Aging In Kenya. The international handbook on aging: current research and developments, 331.

Nkwawir, M. B.(2010). Social Protection Of The Elderly In Cameroon. Unpublished Masters Thesis. Faculty of Social Sciences, Oslo Univerisity

OECD. (2013). Pensions at a Glance 2013: Retirement-income systems in OECD and G20 countries (Paris). Available at: http://www.oecd.org/pensions/pensionsataglance.htm 
Ostir, G. V., Markides, K. S., Peek, M. K., \& Goodwin, J. S. (2001). The association between emotional well-being and the incidence of stroke in older adults. Psychosomatic medicine, 63(2), 210-215.

Palmore, E. B., Whittington, F. J., \& Kunkel, S. (2009). The international handbook on aging: current research and developments. Praeger Publisher.

Peirce, R. S., Frone, M. R., Russell, M., Cooper, M. L., \&Mudar, P. (2000). A longitudinal model of social contact, social support, depression, and alcohol use. Health Psychology, 19(1), 28.

Prenda, K. M., \&Lachman, M. E. (2001). Planning for the future: a life management strategy for increasing control and life satisfaction in adulthood.Psychology and aging, 16(2), 206.

Schulz, J. H., \&Binstock, R. H. (2006). Aging nation: The economics and politics of growing older in America. New York: Praeger.

Smith, S. \& Gove, J. E. (2005). Physical Changes of Aging. University of Florida, IFAS Extension.

Stroebe, W., \&Stroebe, M. (1996). The social psychology of social support. In E. T. Higgins \& A. W. Kruglanski (Eds.), Social psychology: Handbook of basic principles (pp. 597-621). Guilford, New York.

Taylor, B., Mathers, J., Atfield, T., \& Parry, J. (2011). What are the challenges to the big society in maintaining lay involvement in health improvement, and how can they be met? Journal of Public Health, 33 (1), 5-10.

Taylor, S., \& Field, S. (2007).Sociology of health and health care. Oxford: Blackwell.

Topinkova, E., \&Vidovicova, L. (2009). History Of Aging In The Czech Republic (CR). The international handbook on aging: current research and developments, 181.

Zimmer, J. \& Dayton J. (2003). The living arrangements of older adult in sub- saharan Africa in a time of HIV/AIDS. Working Paper No. 169 (Population Council).

\section{AUTHOR'S BIOGRAPHY}

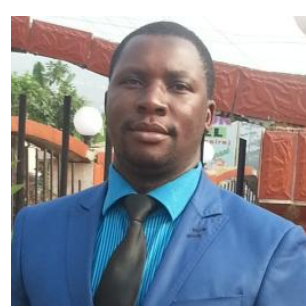

Dr. Tani Emmanuel Lukong, is an Assistant Professor of Inclusive Education and Managerial Psychology. Tani Emmanuel has a PhD in Psychology of Education with triple concentration in, Inclusive Education, Cognitive and Developmental Psychology and Applied cultural Psychology, a Master Degree in Psychology of Education and Bachelor's degree in Special Needs Education. Dr. Tani Emmanuel is a University lecturer and the founder of "Foundation of Scientific Research, Community Based Rehabilitation and Advocacy on Inclusive Education" (Forcaie-Cameroon). A Research Organization aimed at building mutual-help, equal participation, accessible society with love and care through the utilization of available resources in building up an Inclusive Rehabilitation platform which promotes the equal participation of people with disabilities and enhances Community Development. 